\title{
Coronavirus-A Global Emergency
}

\author{
Md. Abdul Ahad *1
}

\begin{abstract} diet, drinking fluids and taking rest.

Keywords: Novel coronavirus, Pandemic, Contagious, COVID-19, SARS, MERS.

Number of References: 40; Number of Correspondence:03.
\end{abstract}

Introduction:Coronavirus is a highly infectious contagious virus producing pandemic throughout the world with high morbidity and mortality. Discussion: Right now, there is no vaccine to prevent human coronavirus infections. But you may able to reduce your risk of getting or spreading an infection by-washing hands often with soap and water for at least 20 seconds, use an alcohol-based hand sanitizer that contains at least 70\% alcohol if soap and water are not available. Avoiding touching your face, nose, or mouth with unwashed hands, use of face mask, avoiding close contact with people who are sick, there is no specific treatment for coronavirus. Conclusion:Treatment aims to relieve the symptoms. Most people will get better on their own. However, you can relieve your symptoms by-taking over-the-counter medicines for pain, fever, and cough. Using a room humidifier or taking a hot shower to help ease a sore throat and cough. Getting plenty of nutritious

*1. Corresponding Author:

Professor Dr. Md. Abdul Ahad

Professor of Gastroenterology \&

Principal, Khulna Medical College, Khulna.

E-mail: drahadbd@yahoo.com

Mobile: 01711-184343

\section{Introduction}

Coronaviruses are a group of viruses that cause diseases in mammals and birds. In humans, the viruses cause respiratory infections which are typically mild, including the common cold; however, rarer forms such as SARS, MERS and the novel Coronavirus causing the current outbreak can be lethal. In cows and pigs they may cause diarrhoea, while in chickens they can cause an upper respiratory disease. There are no vaccines or antiviral drugs that are approved for prevention or treatment.

Coronaviruses are viruses in the subfamily Orthocoronavirinae in the family Coronaviridae, in the order Nidovirales ${ }^{1,2}$. Coronaviruses are enveloped viruses with a positive-sense single-stranded RNA genome and with a nucleocapsid of helical symmetry. The genomic size of coronaviruses ranges from approximately 26 to 32 kilobases, the largest for an RNA virus. The name "Coronavirus" is derived from the Latin corona, meaning crown or halo, which refers to the characteristic appearance of the virus particles (virions): they have a fringe reminiscent of a royal crown or of the solar corona. Human coronaviruses-Severe acute respiratory syndrome (SARS) and Middle East respiratory syndrome.

\section{Novel Coronavirus (COVID-19) \\ Discovery}

Coronaviruses were discovered in the $1960 \mathrm{~s} ;{ }^{3}$ the earliest ones discovered were infectious bronchitis virus in chickens and two viruses from the nasal cavities of human patients with the common cold that were subsequently named human coronavirus 229E and human coronavirus OC434. Other members of this family have since been identified, including SARS-CoV in 2003, HCoV NL63 in 2004, HKU1 in 2005, MERS-CoV in 2012, and 2019-NCOV in 2019; most of these have been involved in serious respiratory tract infections.

\section{Name and Morphology}

The name "Coronavirus" is derived from the Latin corona and the

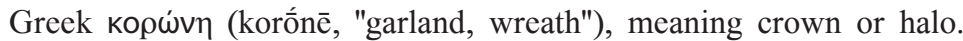
This refers to the characteristic appearance of virions (the infective form of the virus) by electron microscopy, which have a fringe of large, bulbous surface projections creating an image reminiscent of a royal crown or of the solar corona. This morphology iscreated by the viral spike (S) peplomers, which are proteins that populate the surface of the virus and determine host tropism.

\section{Replication}

The infection cycle of coronavirus- Following the entry of this virus into the cell, the virus particle is uncoated and the RNA genome is deposited into the cytoplasm. The coronavirus RNA genome has a $5^{\prime}$ methylated cap and a $3^{\prime}$ polyadenylated tail. This allows the RNA to attach to ribosomes for translation.

\section{Transmissions}

Human coronaviruses usually spread from an infected person to others through ${ }^{5}$. The air by coughing and sneezing, Close personal contact, such as touching or shaking hands, touching an object or surface with the virus on it, then touching your mouth, nose, or eyes before washing your hands, Rarely, feces (poop).

\section{Evolution}

The most recent common ancestor of the coronavirus has been placed at $8000 \mathrm{BCE}^{6}$. They may be considerably older than this. Another estimate places the most recent common ancestor (MRCA) of all coronaviruses around 8100 BCE. The MRCA of Alphacoronavirus, Betacoronavirus, Gammacoronavirus, and Deltacoronavirus have been placed at about $2400 \mathrm{BCE}, 3300 \mathrm{BCE}, 2800 \mathrm{BCE}$ and $3000 \mathrm{BCE}$, respectively. It appears that bats and birds, the warm-blooded flying 
vertebrates, are ideal hosts for the coronavirus gene source (with bats for Alphacoronavirus and Betacoronavirus, and birds for Gammacoronavirus and Deltacoronavirus) to fuel coronavirus evolution and dissemination ${ }^{7}$.

\section{Human Coronaviruses}

Coronaviruses are believed to cause a significant percentage of all common colds in human adults and children. Coronaviruses cause colds with major symptoms, e.g. fever, throat swollen adenoids, in humans primarily in the winter and early spring seasons ${ }^{8}$. Coronaviruses can cause pneumonia, either direct viral pneumonia or a secondary bacterial pneumonia and they can also cause bronchitis, either direct viral bronchitis or a secondary bacterial bronchitis ${ }^{9}$. The much publicized human coronavirus discovered in 2003, SARS-CoV which causes severe acute respiratory syndrome (SARS), has a unique pathogenesis because it causes both upper and lower respiratory tract infections 9 .

\section{Seven Strains of Human Coronaviruses}

1. Human coronavirus 229E (HCoV-229E). 2. Human coronavirus OC43 (HCoV-OC43) 3. SARS-CoV. 4. Human coronavirus NL63 (HCoV-NL63, New Haven coronavirus). 5. Human coronavirus HKU1. 6. Middle East respiratory syndrome coronavirus (MERS-CoV), previously known as novel coronavirus 2012 and HCoV-EMC.7. Novel coronavirus (2019-nCoV), ${ }^{10,11}$ also known as Wuhan pneumonia or Wuhan coronavirus ${ }^{12}$. ('Novel' in this case means newly discovered, or newly originated, and is a placeholder name $)^{10}$. The coronaviruses HCoV-229E, -NL63, -OC43, and -HKU1 continually circulate in the human population and cause respiratory infections in adults and children world-wide ${ }^{13}$.

\section{Symptoms}

The most common symptoms of COVID-19 are fever, tiredness, dry cough and breathing difficulties. Some patients may have aches and pains, nasal congestion, runny nose, sore throat or diarrhea. Rare features are burning sensation in whole body, chills and rigor, cold body, new onset of severe anorexia and anosmia. These symptoms are usually mild and begin gradually. Some people become infected but don't develop any symptoms and don't feel unwell.The symptoms depend on the type of coronavirus and how serious the infection is. If you have a mild to moderate upper-respiratory infection such as the common cold, your symptoms may include-Runny nose, Headache, Cough, Sore throat, Fever, Not feeling well overall. Some coronaviruses can cause severe symptoms. The infections may turn into bronchitis and pneumonia, which cause symptoms such as-fever, which may be quite high if you have pneumonia, cough with mucus, shortness of breath, chest pain or tightness when you breathe and cough. Severe infections are more common in people with heart or lung diseases, people with weakened immune systems, infants, and older adults.

\section{Severe Acute Respiratory Syndrome (SARS)}

In 2003, following the outbreak of severe acute respiratory syndrome (SARS) which had begun the prior year in Asia, and secondary cases elsewhere in the world, the World Health Organization (WHO) issued a press release stating that a novel coronavirus identified by a number of laboratories was the causative agent for SARS. The virus was officially named the SARS coronavirus (SARS-CoV). Over 8,000 people were infected, about $10 \%$ of whom died ${ }^{14}$.

\section{Middle East Respiratory Syndrome (MERS)}

In September 2012, a new type of coronavirus was identified, initially called Novel Coronavirus 2012, and now officially named Middle East respiratory syndrome coronavirus (MERS-CoV) $)^{15,16}$. The World Health Organization issued a global alert soon after ${ }^{17}$. The WHO update on 28 September 2012 stated that the virus did not seem to pass easily from person to person ${ }^{18}$. However, on 12 May 2013, a case of human-to-human transmission in France was confirmed by the French Ministry of Social Affairs and Health ${ }^{18}$. In addition, cases of human-to-human transmission have been reported by the Ministry of Health in Tunisia. Two confirmed cases involved people who seemed to have caught the disease from their late father, who became ill after a visit to Qatar and Saudi Arabia. Despite this, it appears that the virus has trouble spreading from human to human, as most individuals who are infected do not transmit the virus ${ }^{20}$. By 30 October 2013, there were 124 cases and 52 deaths in Saudi Arabia ${ }^{21}$.

\section{Novel Coronavirus (2019-NCOV)}

In December 2019, a pneumonia outbreak was reported in Wuhan, China ${ }^{22}$. On 31 December 2019, the outbreak was traced to a novel strain of coronavirus, ${ }^{23}$ which was labeled as 2019-NCOV by the World Health Organization (WHO) $)^{10,11,24}$. According to Daniel Lucey at Georgetown University, the first human infections must have occurred in November 2019 or earlier ${ }^{25}$. As of 30 January 2020 (16:00 UTC), there have been 214 confirmed deaths and more than 8,230 confirmed cases in the coronavirus pneumonia outbreak ${ }^{26,27,28,29}$. The Wuhan strain has been identified as a new strain of Betacoronavirus from group 2B with an $70 \%$ genetic similarity to the SARS-COV ${ }^{31}$. The virus was suspected to have originated in snakes, ${ }^{30}$ but many leading researchers disagree with this conclusion ${ }^{32}$. Daniel Lucey, an infectious disease specialist at Georgetown University, stated that "Now it seems clear that the seafood market is not the only origin of the virus" 25,33 .

\section{Diagnosis}

To make a diagnosis, your health care provider will-take your medical history, including asking about your symptoms, do a physical exam, may do blood tests, may do lab tests of sputum, a sample from a throat swab, or other respiratory specimens.

\section{Other Animals}

Coronaviruses have been recognized as causing pathological conditions in veterinary medicine since the early 1970s. Except for avian infectious bronchitis, the major related diseases have mainly an intestinal location ${ }^{34}$. 


\section{Diseases}

Coronaviruses primarily infect the upper respiratory and gastrointestinal tract of mammals and birds. They also cause a range of diseases in farm animals and domesticated pets, some of which can be serious and are a threat to the farming industry. In chickens, the infectious bronchitis virus (IBV), a coronavirus, targets not only the respiratory tract but also the urogenital tract. The virus can spread to different organs throughout the chicken ${ }^{35}$. Economically significant coronaviruses of farm animals include porcine coronavirus (transmissible gastroenteritis coronavirus, TGE) and bovine coronavirus, which both result in diarrhea in young animals. Feline coronavirus: two forms, feline enteric coronavirus is a pathogen of minor clinical significance, but spontaneous mutation of this virus can result in feline infectious peritonitis (FIP), a disease associated with high mortality. Similarly, there are two types of coronavirus that infect ferrets: ferret enteric coronavirus causes a gastrointestinal syndrome known as epizootic catarrhal enteritis (ECE), and a more lethal systemic version of the virus (like FIP in cats) known in ferrets as ferret systemic coronavirus $(\mathrm{FSC})^{36}$. There are two types of canine coronavirus $(\mathrm{CCoV})$, one that causes mild gastrointestinal disease and one that has been found to cause respiratory disease. Mouse hepatitis virus (MHV) is a coronavirus that causes an epidemic murine illness with high mortality, especially among colonies of laboratory mice $^{37}$. Sialodacryoadenitis virus (SDAV) is highly infectious coronavirus of laboratory rats, which can be transmitted between individuals by direct contact and indirectly by aerosol. Acute infections have high morbidity and tropism for the salivary, lachrymal and harderian glands ${ }^{38}$. A HKU2-related bat coronavirus called swine acute diarrhea syndrome coronavirus (SADS-CoV) causes diarrhea in pigs $^{39}$. Prior to the discovery of SARS-CoV, MHV had been the best-studied coronavirus both in vivo and in vitro as well as at the molecular level. Some strains of MHV cause a progressive demyelinating encephalitis in mice which has been used as a murine model for multiple sclerosis. Significant research efforts have been focused on elucidating the viral pathogenesis of these animal coronaviruses, especially by virologists interested in veterinary and zoonotic diseases ${ }^{40}$.

\section{Prevention}

Right now, there is no vaccine to prevent human coronavirus infections. But you may able to reduce your risk of getting or spreading an infection by- Washing hands often with soap and water for at least 20 seconds, use an alcohol-based hand sanitizer that contains at least $60 \%$ alcohol if soap and water are not available. Avoiding touching your face, nose, or mouth with unwashed hands, use face mask. Avoiding close contact with people who are sick, avoid mass gatherings, cleaning and disinfecting surfaces that you frequently touch, covering coughs and sneezes with a tissue, then throw away the tissue and wash your hands, Staying home when sick.

\section{Treatment}

There is no specific treatment for coronavirus. Treatment aims to relieve the symptoms. Most people will get better on their own. However, you can relieve your symptoms by- Taking over-the-counter medicines for pain, fever, and cough. However, do not give aspirin to children. And do not give cough medicine to children under four.Using a room humidifier or taking a hot shower to help ease a sore throat and cough. Getting plenty of rest, drinking fluids. If you are worried about your symptoms, contact your health care provider. For severe cases, treatment should include care to support vital organ functions. People who think they may have been exposed to 2019-nCoV should contact your healthcare provider immediately.

\section{Conclusion}

During previous outbreaks due to other coronavirus (Middle-East Respiratory Syndrome (MERS) and Severe Acute Respiratory Syndrome (SARS)), human to human transmission occurred through droplets, contact and fomites, suggesting that the transmission mode of the 2019-NCOVID can be similar. The basic principles to reduce the general risk of transmission of acute respiratory infections include the following: Avoiding close contact with people suffering from acute respiratory infections. Frequent hand-washing, especially after direct contact with ill people or their environment. Avoiding unprotected contact with farm or wild animals.People with symptoms of acute respiratory infection should practice cough etiquette (maintain distance, cover coughs and sneezes with disposable tissues or clothing, and wash hands). Within healthcare facilities, enhance standard infection prevention and control practices in hospitals, especially in emergency departments. WHO does not recommend any specific health measures for travelers. In case of symptoms suggestive of respiratory illness either during or after travel, the travelers are encouraged to seek medical attention and share their travel history with their health care provider. Proper nutrition and hydration are vital. People who eat a well-balanced diet tend to be healthier with stronger immune systems and lower risk of chronic illnesses and infectious diseases. So you should eat a variety of fresh and unprocessed foods every day to get the vitamins, minerals, dietary fibre, protein and antioxidants your body needs. Drink enough water.

\section{Conflict of Interest: None.}

\section{Acknowledgement}

I am very much grateful to the COVID-19 patients who sacrificed their lives during this pandemic. I am also grateful to the respected COVID-19 fighter doctors and health workers who also dedicated their lives in this war against invisible enemy and pray for their departed souls.

\section{References}

1. Jump up to:a b de Groot RJ, Baker SC, Baric R, Enjuanes L, Gorbalenya AE, Holmes KV, et al. (2011). "Family Coronaviridae". In AMQ King, E Lefkowitz, MJ 
Adams, EB Carstens (eds.). Ninth Report of the International Committee on Taxonomy of Viruses. Elsevier; Oxford. 2011: 806-828.

https://doi.org/10.1016/B978-0-12-384684-6.00068-9

2. International Committee on Taxonomy of Viruses (24 August 2010). "ICTV Master Species List 2009 - v10" (xls).

3. "Coronavirus: Common Symptoms, Preventive Measures, \& How to Diagnose It". Caringly Yours. 28 January 2020. Retrieved 28 January 2020.

4. Geller C, Varbanov M, Duval RE (November 2012). "Human coronaviruses: insights into environmental resistance and its influence on the development of new antiseptic strategies".Viruses.2012; 4 (11): 3044-3068.

https://doi.org/10.3390/v4113044

\section{PMid:23202515 PMCid:PMC3509683}

5. "Transmission of Novel Coronavirus (2019-nCoV) CDC". www.cdc.gov. 31 January 2020. Retrieved 1 February 2020.

6. Wertheim JO, Chu DK, Peiris JS, Kosakovsky Pond SL, Poon LL. "A case for the ancient origin of coronaviruses". Journal of Virology. June 2013; 87 (12):7039-7045.

https://doi.org/10.1128/JVI.03273-12

\section{PMid:23596293 PMCid:PMC3676139}

7. Woo PC, Lau SK, Lam CS, Lau CC, Tsang AK, Lau $\mathrm{JH}$, et al. "Discovery of seven novel Mammalian and avian coronaviruses in the genus deltacoronavirus supports bat coronaviruses as the gene source of alphacoronavirus and betacoronavirus and avian coronaviruses as the gene source of gammacoronavirus and deltacoronavirus". Journal of Virology. April 2012; 86 (7):3995-4008.

https://doi.org/10.1128/JVI.06540-11

PMid:22278237 PMCid:PMC3302495

8. Liu P, Shi L, Zhang W, He J, Liu C, Zhao C, et al. "Prevalence and genetic diversity analysis of human coronaviruses among cross-border children". Virology Journal. November 2017; 14 (1): 230.

https://doi.org/10.1186/s12985-017-0896-0

\section{PMid:29166910 PMCid:PMC5700739}

9. Jump up to:a b Forgie S, Marrie TJ. "Healthcare-associated atypical pneumonia". Seminars in Respiratory and Critical Care Medicine. February 2009; 30 (1): 67-85.

10. Jump up to:a b "Laboratory testing of human suspected cases of novel coronavirus (nCoV) infection. Interim guidance, 10 January 2020" (PDF). Archived (PDF) from the original on 20 January 2020. Retrieved 14 January 2020 .

11. Jump up to:a b c "Novel Coronavirus 2019, Wuhan, China CDC". www.cdc.gov.23 January 2020. Archived from the original on 20 January 2020. Retrieved 23 January 2020.
12. "Pneumonia of unknown cause - China". World Health Organization. 5 January 2020. Archived from the original on 7 January 2020. Retrieved 23 January 2020.

13. Corman VM, Muth D, Niemeyer D, Drosten C. "Hosts and Sources of Endemic Human Coronaviruses". Advances in Virus Research. 2018; 100: 163-188.

https://doi.org/10.1016/bs.aivir.2018.01.001

PMid:29551135 PMCid:PMC7112090

14. Jump up to:a b Li F, Li W, Farzan M, Harrison SC. "Structure of SARS coronavirusspike receptor-binding domain complexed with receptor". Science. September 2005; 309 (5742):1864-1868.

https://doi.org/10.1126/science. 1116480

PMid:16166518

15. Doucleef M (26 September 2012). "Scientists Go Deep On Genes Of SARS- Like Virus". Associated Press. Archived from the original on 27 September 2012. Retrieved 27 September 2012.

16. Falco M (24 September 2012). "New SARS-like virus poses medical mystery". CNN Health. Archived from the original on 1 November 2013. Retrieved 16 March 2013.

17. "New SARS-like virus found in Middle East". Al-Jazeera. 24 September 2012. Archived from the original on 9 March 2013. Retrieved 16 March 2013.

18. Kelland K (28 September 2012). "New virus not spreading easily between people: WHO". Reuters. Archived from the original on 24 November 2012. Retrieved 16 March 2013.

19. Nouveau coronavirus- Point de situation : Un nouveau cas d'infection confirmé Archived 8 June 2013 at the Wayback Machine (Novel coronavirus - Status report: A new case of confirmed infection). 12 May 2013.

20. CDC (2 August 2019). "MERS Transmission". Centers for Disease Control and Prevention. Archived from the original on 7 December 2019. Retrieved 10 December 2019.

21. "Novel coronavirus infection - update". World Health Association. 22 May 2013. Archived from the original on 7 June 2013. Retrieved 23 May 2013.

22. The Editorial Board (29 January 2020). "Is the World Ready for the Coronavirus? - Distrust in science and institutions could be a major problem if the outbreak worsens". The New York Times. Retrieved 30 January 2020.

23. "WHO Statement Regarding Cluster of Pneumonia Cases in Wuhan, China". www.who.int. 9 January 2020. Archived from the original on 14 January 2020. Retrieved 10 January 2020.

24. "2019 Novel Coronavirus infection (Wuhan, China): Outbreak update". Canada.ca. 21 January 2020.

25. Jump up to:a b Cohen, Jon (26 January 2020). "Wuhan seafood market may not be source of novel virus spreading globally". ScienceMag American Association for the 
Advancement of Science. (AAAS). Archived from the original on 27January 2020. Retrieved 29 January 2020.

26. "Operations Dashboard for ArcGIS". gisanddata.maps. arcgis.com. The Center for Systems Science and Engineering (CSSE) is a research collective housed within the Department of Civil and Systems Engineering (CaSE) at Johns Hopkins University (JHU). 28 January 2020. Archived from the original on 28 January 2020. Retrieved 28 January 2020.

27. Kotyk, Alyse (28 January 2020). "B.C. confirms province's first presumptive positive case of new coronavirus". CTV News. Archived from the original on 28 January 2020. Retrieved 28 January2020.

28. James Griffiths; Nectar Gan; Tara John; Amir Vera. "Wuhan coronavirus death toll rises, as city imposes transport lockdown". CNN.

29. "China virus death toll mounts to 25 , infections spread". Reuters. 24 January 2020. Retrieved 24 January 2020.

https://doi.org/10.1044/leader.PPL.25012020.22

30. "Clinical Key". www.clinicalkey.com. Archived from the original on 25 April 2013. Retrieved 23 January 2020.

31. Luo, Guangxiang (George); Gao, Shou Jiang (2020).

"Global Health Concern Stirred by Emerging Viral Infections". Journal of Medical Virology.

https://doi.org/10.1002/jmv.25683

32. "No, the Wuhan Virus Is Not a 'Snake Flu"'. Wired. Archived from the original on 24 January 2020. Retrieved 24 January 2020.

33. Eschner, Kat (28 January 2020). "We're still not sure where the Wuhan coronavirus really came from". Popular Science. Archivedfrom the original on 29 January 2020. Retrieved 30 January 2020.
34. Murphy, FA; Gibbs, EPJ; Horzinek, MC; Studdart MJ. Veterinary Virology. Boston: Academic Press. 1999: 495-508.

https://doi.org/10.1016/B978-012511340-3/50033-7

PMCid:PMC2362309

35. Bande F, Arshad SS, Bejo MH, Moeini H, Omar AR. "Progress and challenges toward the development of vaccines against avian infectious bronchitis". Journal of Immunology Research. 2015: 1-12.

https://doi.org/10.1155/2015/424860

PMid:25954763 PMCid:PMC4411447

36. Murray J (16 April 2014). "What's New with Ferret FIP-like Disease?" (xls). Archived from the original on 24 April 2014. Retrieved 24 April 2014.

37. Weiss SR, Navas-Martin S. "Coronavirus pathogenesis and the emerging pathogen severe acute respiratory syndrome coronavirus". Microbiology and Molecular Biology Reviews. December 2005; 69 (4): 635-664.

https://doi.org/10.1128/MMBR.69.4.635-664.2005

PMid:16339739 PMCid:PMC1306801

38. "Rat Coronavirus- an overview Science Direct Topics". www.Sciencedirect.com

39. Fatal swine acute diarrhoea syndrome caused by an HKU2-related coronavirus of bat origin Archived 31 May 2019 at the Wayback Machine, Peng Zhou, Hang Fan, Tian Lan, Xing-Lou Yang, Wei-Feng Shi, Wei Zhang, et al. Nature. 5 April 2018.

40. Tirotta E, Carbajal KS, Schaumburg CS, Whitman L, Lane TE. "Cell replacement therapies to promote remyelination in a viral model ofdemyelination". Journal of Neuroimmunology. July/2010; 224 (1-2): 101-107.

https://doi.org/10.1016/j.jneuroim.2010.05.013

PMid:20627412 PMCid:PMC2919340 